\title{
Parent Perspectives on Inclusive Education in Rural Alberta, Canada
}

\author{
Tim Loreman \\ Concordia University College of Alberta \\ Donna McGhie-Richmond \\ University of Victoria \\ Jennifer Barber and Judy Lupart \\ University of Alberta
}

\begin{abstract}
This paper is one of a series of papers examining inclusive education in the context of a rural Canadian school district that has adopted a philosophy of inclusion. The results of a survey of 438 parents on their views about aspects of inclusive education at their youngest child's school are reported. The results indicate that the majority of parents were generally positive in their views about and experiences with the inclusive school environment and links to the local community; however, parents were by no means unanimous in their level of comfort with inclusive education. Tensions were found to exist, and differences in the experience of parents of children who had identified exceptionalities were evident. This study points to the paucity of research on parents and inclusive education and provides some direction for future work in the area.
\end{abstract}

Developing out of perspectives on social justice for children with exceptionalities, inclusive education has become a practice that is evident in many areas of the world, including Canada. Following an inclusive approach means that all students, regardless of differences, have their individual educational (and other) needs met within the regular classroom and school context (Andrews \& Lupart, 2000; Loreman, 1999). While it is acknowledged that inclusive education is a term that can be applied to the education of children from a wide array of diverse backgrounds - including culture, gender, sexual orientation, and other areas of difference - this study focuses on inclusion from the perspective of diverse ability, primarily disability, but also with a secondary focus on giftedness. While recognizing that the main focus is disability, we have grouped these under the common term of "exceptionality" throughout the majority of this paper as they both feature in the analysis, except where the discussion is specific to one or the other of these groups. The inclusion of a student with an exceptionality refers to the involvement of that student in all activities and contexts in which students without exceptionalities are involved. In 
these environments, exceptionality is not used as a basis for exclusion. The extent to which schools include students with exceptionalities, however, has wider implications for all students in terms of context and environment. It is for this reason that the sample used in this study, parents, goes beyond only parents of children with exceptionalities to encompass the views of the wider parent body in the district under examination.

This is one of a series of papers connected to a wider study examining inclusive education in the Pembina Hills Regional School District \#7 (PHRD) in Alberta, Canada (see also Loreman, Lupart, McGhie-Richmond, \& Barber, 2008; Loreman, McGhie-Richmond, Barber, \& Lupart, 2008; McGhie-Richmond, Barber, Lupart, \& Loreman, 2009a; McGhie-Richmond, Barber, Lupart, \& Loreman, 2009b). Each paper in this series presents results on important components of inclusion based on survey research conducted with various stakeholder groups including teachers, students, administrators, and teaching assistants in a rural Canadian context. This paper focuses on one more important stakeholder group: parents. Parents are critical to the success of inclusive education, and their views should be of interest to any school jurisdiction attempting to follow an inclusive approach.

As outlined in a previous paper in this series (Loreman, Lupart et al., 2008), this study is unique in the province of Alberta and addresses an identified deficit in research on inclusive education in rural Canada. It takes place in a school district that deliberately does not offer ability-based segregated programs, has a district-wide policy of inclusion, and has anecdotal evidence of excellent practice in inclusive education. In order to add some objective, empirical evidence to support their claims to inclusiveness, and to identify areas which need improvement along with "best practices" to encourage in others, PHRD enthusiastically partnered with the three universities involved in this research.

\section{Parents and Inclusive Education}

Inclusion, as discussed above, is considered here to be the policies and practices implemented by a school or school district that allow children of all abilities to fully participate in academic and social activities in a regular classroom setting. This study examines a number of facets relevant to inclusive education and parents, including parental perceptions of how their child is valued, and how their needs are met, at school; parental attitudes towards inclusion; levels of family community involvement; parental ideas about the encouragement of a sense of personal responsibility in students; and parental and child influence over activities in the school and levels of input into decisions. Certainly these facets do not cover all the areas in which parents may have views about inclusive education that can inform practice; however, they do represent some key areas previously identified as being germane to the success of inclusive education (Lupart, Whitley, Odishaw, \& McDonald, 2006).

Parental ideas about the extent to which their child is valued and needs are met in inclusive schools. One of the premises of inclusive education is that it better meets the academic and social needs of all students. It is, therefore, important that all students feel valued and that their needs are met. Parents of children without exceptionalities attending inclusive schools may express concern that the needs of their child may not be met and that they will become lost in the system. Duhaney and Salend (2000) provided a review of studies examining the perceptions of parents of children without exceptionalities towards inclusion. Their analysis revealed generally positive parental perspectives, particularly with respect to social-emotional factors. 
The studies also revealed that parents of children without exceptionalities regard inclusive classrooms to be educationally beneficial for their children. Duhaney and Salend, however, noted that some studies revealed parental concern about the instructional effectiveness of inclusive placements for their child, expressing unease about the skills of the teacher, the amount of time to provide effective instruction, as well as the potential for children to emulate inappropriate behaviour.

Parents of children with exceptionalities worry about ensuring social acceptance, but also that their children receive the appropriate education. The literature suggests that some parents of children in inclusive settings, particularly those with disabilities, might prefer to move their child to a special school in the later primary and secondary grades (Hanson et al., 2001; Jenkinson, 1998; Kasari, Freeman, Bauminger, \& Alkin, 1999). Parents' reasoning for this move cite that social and academic gaps widen as children age, thus a special school setting would be more beneficial for the child (Jenkinson, 1998). Some parents note that the attitude and experience of teachers in special schools is more understanding and beneficial to children with exceptionalities. In addition, curriculum is seen to be a factor. Many parents view mainstreamed curriculum as having little to offer their child in the secondary grades. Too often the curriculum is adapted to such an extent that it rarely resembles the original form and is often deemed to be impractical. For many parents, academic expectations for their child vary with the level of disability. For example, parents of children with moderate to severe disabilities indicate they would prefer instruction of life skills at the secondary level as opposed to academic skills. Though parents indicated that they feel less positive about inclusion as their child ages, the majority of parents still indicated that further efforts are needed to promote a positive view of children with exceptionalities in general classrooms (Jenkinson, 1998). It follows, then, that a successful inclusive school district is one in which student needs are met to the point where parents are satisfied and do not feel that their child's psychological, social, and academic needs might be better met in other settings.

Parental attitudes towards inclusion. When it comes to attitudes towards inclusion, there are a range of opinions for parents both with and without children with exceptionalities. Frequently, parents support the idea of inclusion from a philosophical standpoint, but may have concerns when it comes to practical implementation for specific children, including their own (Kniveton, 2004; Leyser \& Kirk, 2004). Many of these differences seem to be between parents of children with exceptionalities and parents of typically achieving children, but there is little empirical evidence on these issues.

There are a handful of studies that examine the perspective of parents whose children do not have exceptionalities. Particularly in the primary grades, parents of typically achieving children report that they support the idea of inclusion and would allow their children to play with children with exceptionalities (Kalyva, Georgiadi, \& Tsakiris, 2007). However, parents of children with exceptionalities tend to have varying opinions on the matter. In particular, parents of children with cognitive disabilities tend to be more reluctant to allow their children to participate in regular social activities largely because they fear social rejection of their child (Saloviita, Italinna, \& Leinonen, 2003; Westling, 1997). Given that parents of children with exceptionalities face higher levels of stress and concern over facilitating their child's everyday activities than parents of typically achieving children (Oelufsen \& Richardson, 2006; Stainton \& Besser, 1998), these results are not surprising. For the most part, however, parents with typically achieving children support inclusion to the extent that it does not interfere with the learning of other children in the classroom (Hanson et al., 2001; Kniveton, 2004). This research points to a trend of 
acceptance of the general idea, but hesitation when it comes to the practical implementation of an inclusive model. That is, despite inclusion being seen as a good thing in theory, parents of typically achieving children may hesitate to continue their support if inclusion negatively affects their child's education.

With respect to parents of children with exceptionalities, there are myriad feelings on inclusion. Parental attitude varies depending on educational level and gender of the parent, age, and exceptionality of the child, as well as the particular skills the parent wishes the child to obtain (Kniveton, 2004; Saloviita et al., 2003; Westling, 1997). The literature suggests that parents with a higher level of education are more positive about inclusion (Leyser \& Kirk, 2004). In addition, female parents tend to be more positive than male parents, although this gap narrows as the child becomes older (Hadadian \& Merbler, 1995; Saloviita et al., 2003; Trute, HiebertMurphy, \& Levine, 2007). Parents of younger children are more likely to be positive about inclusive education than parents of older children, which may be due to the social gaps that appear between children as they age and recognize differences amongst each other (Jenkinson, 1998; Leyser \& Kirk, 2004) or because parents perceive that the services that their child receives as he or she progresses into the older grades are not appropriate or adequate (Brodin \& Lindstrand, 2007; Prezant \& Marshak, 2006). Finally, parents are more supportive of inclusion for children with mild disabilities as opposed to moderate and severe disabilities (Kasari et al., 1999; Leyser \& Kirk, 2004). This is likely because children with mild disabilities are perceived to be less disruptive to the class as a whole (Jenkinson, 1998). However, it may also reflect a deeper bias that separate schooling is more appropriate for students with severe physical, emotional, and academic needs. In sum, many parents seem to be positive about inclusion as an idea, but have mixed feelings on the practical implementation based on the needs and age of the child.

Inclusion and involvement in the local community. Including students with exceptionalities has an impact on both classroom community and the community-at-large. At the micro-level of the classroom, friendships with typically achieving peers are more evident in inclusive settings (Kennedy \& Shukla, 1997). This is not surprising as typically achieving students interact more with students with exceptionalities in inclusive settings as opposed to segregated settings. Allowing the opportunity for friendships to form is the first step in breaking down barriers between students with and without exceptionalities. However, inclusion also has an impact on the larger community. Students who are included tend to have more involvement and friendships in their local communities (McDonnell, Hardman, Hightower, \& Kiefer-O'Donnell, 1991). By including students in the regular classroom, they become part of the larger social fabric and networks that go along with school.

Inclusion also appears to have long-term benefits outside the school setting. There is evidence to suggest that students with disabilities who are included become adults who spend more time in the local community in both leisure pursuits and employment (Alper \& Ryndak, 1992). This has impacts both in terms of the development of the individual's social skills and selfesteem and the development of the community. Increasingly, individuals with disabilities are being seen as valued contributors to the workforce by governments and private organizations as many large companies have created programs to attract individuals with disabilities for employment (National Educational Association of Disabled Students, 2008). This is reflected in national employment statistics that indicate that employment for Canadians with disabilities grew from 49.3\% to 53.5\% between 2001 and 2006 (Statistics Canada, 2008). Thus, inclusion may facilitate positive feelings both from the individual with the exceptionality towards his or her community and from the community towards individuals with exceptionalities. 
Inclusion and encouraging personal responsibility and independence. Research suggests that the foretold benefits of inclusion have come to fruition for students both with and without exceptionalities. The opportunity to interact with students with exceptionalities has been shown to allow typically achieving students to develop a sense of acceptance for diversity and of personal responsibility. For instance, these students learn to value and respect students with exceptionalities (Kishi \& Meyer, 1994), incorporating respect for diversity into their personal value system. It has been also shown that students without exceptionalities experience improved selfesteem through friendship or peer-tutoring programs with students with exceptionalities (Staub, Spaulding, Peck, Gallucci, \& Schwartz, 1996). This not only allows typically achieving students to take on a leadership role, but also to become empathetic to the limitations and, more importantly, the strengths of students with exceptionalities. Thus, inclusion offers an opportunity for personal growth of all students.

Inclusion has also been shown to encourage independence in students with exceptionalities. Inclusive settings have been shown to be important in developing not only academic, but also general knowledge for students with disabilities (Davern \& Schnorr, 1991). This is to say, students with disabilities in inclusive classrooms benefit not only academically from interaction with their typically achieving peers, but also learn culturally relevant societal behaviours. Students with disabilities in inclusive settings also demonstrate enhanced development of appropriate social and communication skills (Bennett, Deluca, \& Bruns, 1997; Hunt, FarronDavis, Beckstead, Curtis, \& Goetz, 1994). These skills are fundamentally important in facilitating the functionality of an individual with an exceptionality in society. Not only are these skills important for school, but also for everyday life such as applying for jobs, and gaining enough independence to care for oneself with reduced support. Indeed, graduates with disabilities from inclusion programs have been found to earn up to three times the salary of graduates from segregated programs and cost half as much to support in the community (Alper \& Ryndak, 1992).

Inclusion and the importance of parent-school partnerships. It has been suggested that one of the contributing factors to the success of inclusion is the quality of the relationship between parents of children with exceptionalities and school staff (Bush, 2005). Parents have unique knowledge about their child's abilities and are often able to facilitate school staffs' understanding about the child so that his or her education can be delivered more effectively. For instance, parent knowledge about behavioural cues, academic interests, and social capacity, to name a few, are especially helpful in developing program plans for that student (Muhlenhaupt, 2002). Like any parent, the continuity of enforcing school guidelines at home helps to encourage the academic and social growth of children with exceptionalities.

Although most school policies welcome parental input into the education of their children, it is often found that parents of students with exceptionalities face barriers to genuine partnership when it comes to the educational decision making for their children (Cole, 2007; Norwich, Griffiths, \& Burden, 2005; O'Connor, 2008). For example, a longitudinal study by Norwich et al. (2005) about the relationship between schools and parents of children with dyslexia found that there is often a power-sharing struggle between parents who want the best educational opportunities for their children and professionals whose assessments of the child's abilities may not always coincide with the wishes of the parent. Parents often felt like their expertise of their child was not valued in the parent-school partnership, whereas professionals felt that parents could often become overly aggressive in their push to gain opportunities for their children. Norwich et al. suggested that the success of a partnership lies in effective communication and common goal setting for individual children, with professionals and parents alike 
realizing that each child, and hence the opportunities for that child, must be considered on a caseby-case basis. These findings have been echoed by other researchers who suggest that the parent-school relationship requires a paradigm shift on the part of professionals from being "experts" in their field to becoming partners and accepting multiple perspectives on children with disabilities (O’Connor, 2008; Osler \& Osler, 2002).

\section{Objectives}

The aim of this research is to explore the views of parents of children attending a rural Alberta school district with a history of inclusive practice and an anecdotal record of success in this area. Specifically, the study sets out to (a) identify the views of parents with children attending schools in PHRD relative to inclusive education in the district; (b) examine and explain any differences between the inclusive school experience of parents of students with and without exceptionalities; and (c) examine and explain any other significant differences in responses based on demographic variables.

\section{Method}

\section{Instrumentation}

The Diversity, Individual Development, Differentiation survey (DIDDs), developed by Lupart et al. (2006), was initially selected as the means for quantifying parent views in areas relevant for overall school functioning and specific to inclusion. As noted by Lupart et al., the original DIDDs surveys covered a range of themes including school culture, safety and security, school development, student entitlement, and learning and teaching. Immediately prior to this study, the instrument was further modified through a process of revisions by an expert focus group and then data reduction. It is this modified scale, which we have labeled the Parent Perceptions of Inclusion in Rural Canada (PPIRC) scale, that is used as the basis for reporting the results of the parent survey.

\section{Procedure}

The questionnaire with an accompanying plain-language explanatory statement was mailed to all families of children in PHRD in October-November 2007 following notification in a newsletter from the school district that the surveys would be administered. When completing the survey, parents were asked to consider their experience with their youngest child in school because many of the items required focus on a single, individual child. Appropriate ethical permission was gained from each participating university prior to survey administration. Parents who chose to participate completed the survey and returned it directly to the researchers in postage-paid envelopes. No identifying information was requested or provided on the surveys and access to the data was limited to the research team conducting the administration and/or analysis, all of whom had signed confidentiality agreements. 


\section{Sample}

A total of 438 parents completed the parent survey, representing approximately $18 \%$ of families of children registered in PHRD from kindergarten to Grade 12 at the time of survey administration. While the number of respondents was high, the percentage relative to the overall parent population in the district was more modest, and the degree to which this percentage was representative of wider views in the district might be questioned. However, with respect to sample size, a common guide used in statistical data reduction - to which the data in this study were subjected - is a participant to item ratio of approximately 10:1 (Costello \& Osborne, 2005). The 438 participants in this study responded to a 22-item scale, producing a ratio of approximately 20:1. While this does not necessarily imply that the responses were representative of the wider body of parents in the district, it does speak to the appropriateness of the scale and sample size for the subsequent analysis. Further, Dey (1997) has noted a decline in survey response rates over the past 50 years, with response rates of approximately $20 \%$ to mail-in surveys being now not uncommon. That being said, given that nothing is known about those who did not respond, it is difficult to gauge the impact of non-response on this study. Of the respondents, the vast majority (394 or $90 \%$ ) were female parents, with $7.5 \%$ (33) being male, and the remaining $2.5 \%$ (11) not reporting gender.

Many of the survey questions were framed relative to one child. Consequently, parents were asked to focus on their youngest child when completing the survey and were asked to indicate the grade level of this child. This request skewed the reporting towards younger grades. However, it was felt that asking parents to focus on one child - and stipulating who that child should be-created some level of consistency in reporting. Of the total sample, 17 parents $(3.9 \%)$ indicated that their youngest child was in kindergarten, 212 parents $(48.4 \%)$ indicated that their youngest child was in grade $1-3$, and 126 parents $(28.8 \%)$ indicated that their youngest child was in grade 4-6. A further 55 parents (12.6\%) indicated that their youngest child was in grade $7-9$ and 27 parents $(6.2 \%)$ indicated that their youngest child was in grade $10-12$. Of the total sample, $201(45.9 \%)$ sent their children to school in the communities of Westlock and Barrhead, while $212(48.4 \%)$ sent their children to school in other communities (this information was not available for 25 or $5.7 \%$ of cases). A total of $82.2 \%(n=360)$ of respondents did not have children with identified exceptionalities according to Alberta Provincial criteria. The remaining $17.8 \%(n=78)$ did. Table 1 outlines the Provincial special education categories of children from the sample group.

\section{Data Reduction: The PPIRC Scale}

The original 56 Likert-scaled items of the DIDDs parent survey underwent data reduction (i.e., principal components analysis) to establish a smaller meaningful number of comprehensive items (22) designed to capture the nomological network associated with inclusive education in Canadian schools as it relates to parents. Item selection for the final scale for reporting was based on the magnitude of individual item loadings as seen in the varimax rotated component matrix, with the added criteria that each item load significantly on only one subscale to facilitate a simple, unidimensional interpretation (Thurstone, 1947; see Table 2). Responses to the items on the scale were distributed normally. The Kaiser-Meyer-Olkin value was .83, exceeding the recommended value of .6 (Kaiser, 1970, 1974), and a highly significant measure of sphericity was evident (Bartlett's, 1954, Test of Sphericity; $\left.\chi^{2}(231)=2581.2 ; p=0.000\right)$, further supporting both 
Table 1

Alberta Special Education Categories of Children of Parent Respondents

\begin{tabular}{lrr}
\hline \multicolumn{1}{c}{ Category } & Frequency & Percent \\
\hline (Early Childhood services only) Mild to moderate communication disabilities/delay. & & \\
Physical or medical disability. Multiple disability. & 3.0 & 0.7 \\
Severe emotional/behavioural disability & 15.0 & 3.4 \\
Severe multiple disability & 1.0 & 0.2 \\
Severe physical or medical disability & 11.0 & 2.5 \\
Blindness & 1.0 & 0.2 \\
(Early Childhood Services only) child with severe delay involving language & 2.0 & 0.5 \\
Mild cognitive disability & 2.0 & 0.5 \\
Emotional/behavioural disability & 19.0 & 4.4 \\
Communication disability & 13.0 & 3.0 \\
Physical/medical disability & 2.0 & 0.5 \\
Multiple disability & 5.0 & 1.1 \\
Gifted or talented & 4.0 & 0.9 \\
Total & 78.0 & 17.8 \\
No identified special need & 360.0 & 82.2 \\
Total & 438.0 & 100.0 \\
\hline
\end{tabular}

the approach taken (principal components analysis with Varimax rotation) and the suitability of the items selected to characterize the scale construct.

An inspection of Catell's (1966) scree plot revealed a clear break after the fifth component. The results of Parallel Analysis showed five components with eigenvalues exceeding the corresponding criterion values for a randomly generated data matrix of the same size (56 variables by 438 respondents). The decision was made to retain the first five components for further investigation. A final evaluation of each item included in the subscales was verified by our understanding of the conceptual and practical aspects of inclusive education practices. The 5component solution explained a total of $55.07 \%$ of the total variance (Component $1=21.65 \%$; Component $2=12.08 \%$; Component $3=9.60 \%$; Component $4=6.82 \%$; Component $5=4.92 \%$ ). Varimax rotation was subsequently performed. The rotated solution revealed the presence of simple structure (Thurstone, 1947; see Table 2), with all five components showing a number of strong loadings.

Items that loaded on each of the five components had strong, clear, conceptual links. Items on Factor One are indicative of parental perceptions of how their child is valued, and how their needs are met, at school. Items on Factor Two address attitudes towards inclusion. Factor Three items are linked by the common theme of community involvement. Items on Factor Four address the theme of the school encouraging a sense of personal responsibility in students. Items in Factor Five are linked by the common theme of parental and child influence over activities in the school and levels of input into decisions.

The Cronbach alpha coefficient for the entire scale was .80 . The Cronbach alpha coefficient for each of the five components was calculated at $.81, .81, .74, .62$, and .53 respectively. 
Table 2

Principal Components Analysis of 22 Items from the DIDDs Parent Survey

\begin{tabular}{|c|c|c|c|c|c|}
\hline \multicolumn{6}{|l|}{ Rotated Component Matrix(a) } \\
\hline & \multicolumn{5}{|c|}{ Component } \\
\hline & 1 & 2 & 3 & 4 & 5 \\
\hline My child feels that his/her teachers like him/her. & .744 & .069 & .151 & .046 & .123 \\
\hline My child's teachers did not do a good job of meeting his/her needs this & & & & & \\
\hline 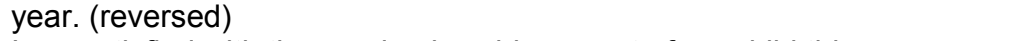 & .715 & .057 & .021 & .099 & .160 \\
\hline I am satisfied with the academic achievement of my child this year. & .691 & .023 & -.007 & .234 & .147 \\
\hline My child is encouraged to take pride in his/her own achievements. & .675 & .136 & .029 & .209 & .060 \\
\hline I feel that my child is valued by the school. & .655 & .125 & .108 & .362 & .156 \\
\hline \multicolumn{6}{|l|}{ Inclusion (the full participation of students with special needs in regular } \\
\hline classrooms) provides benefits for all students. & .060 & .836 & .016 & -.051 & .096 \\
\hline I think that including students with special needs in the classroom takes & & & & & \\
\hline away from the education of other students in the class. (reversed) & .036 & .809 & -.035 & -.003 & .152 \\
\hline I think that students with special needs can have greater success in & & & & & \\
\hline $\begin{array}{l}\text { special classes. (reversed) } \\
\text { I think that all students, including those with special needs, should at- }\end{array}$ & .086 & .744 & .051 & -.047 & (00\% \\
\hline tend their local neighbourhood school. & -.020 & .706 & .001 & .197 & -.141 \\
\hline $\begin{array}{l}\text { Inclusion provides students with special needs the opportunity to reveal } \\
\text { their learning potential. }\end{array}$ & .178 & .612 & -.015 & .054 & .126 \\
\hline \multicolumn{6}{|l|}{ My child takes lessons outside of school (music, dance, martial arts, } \\
\hline swimming). & .307 & -.012 & .732 & -.104 & -.174 \\
\hline My child participates in group activities outside of school (sports, clubs). & .321 & -.050 & .703 & -.162 & -.071 \\
\hline I often take my child to plays or musical events. & -.161 & .016 & .694 & .296 & .269 \\
\hline I rarely take my child to community events. (reversed) & .052 & -.028 & .675 & .127 & .146 \\
\hline I often take my child to museums and galleries. & -.246 & .170 & .614 & .258 & .255 \\
\hline My child is encouraged to take responsibility for his or her own learning. & .218 & -.036 & .003 & .711 & -.005 \\
\hline The school's approach to discipline encourages self discipline. & .202 & .054 & .082 & .649 & .175 \\
\hline $\begin{array}{l}\text { At school, my child is encouraged to explore views that are different } \\
\text { from his or her own. }\end{array}$ & .257 & .067 & .131 & .626 & .173 \\
\hline \multicolumn{6}{|l|}{ I do not completely understand my child's Provincial Achievement Test } \\
\hline results. (reversed) & -.005 & -.078 & .109 & .023 & .674 \\
\hline My child is not given a choice over learning activities. (reversed) & .227 & .129 & -.050 & .026 & .630 \\
\hline Students are not involved in making classroom rules. (reversed) & .169 & .088 & .086 & .187 & .569 \\
\hline There are opportunities for me to influence school policy and practice. & .280 & .149 & .117 & .178 & .462 \\
\hline
\end{tabular}

Note. Extraction method: Principal Component Analysis; rotation method: Varimax with Kaiser Normalization.

a. Rotation converged in 7 iterations.

\section{Results}

The mean score for the PPIRC scale was calculated at $3.74(S D=0.375)$. Unanswered questions were deleted from the analysis using pairwise deletion. Mean scores for each of the factors and individual items retained in the factors are presented in Table 3.

\section{Demographic Analysis}

A demographic analysis revealed noteworthy results with respect to only a single dimension: child's exceptionality. The results relating to parent gender were statistically significant on 
Table 3

The PPIRC Scale Including Factors and Items Reported with Means and Standard Deviations

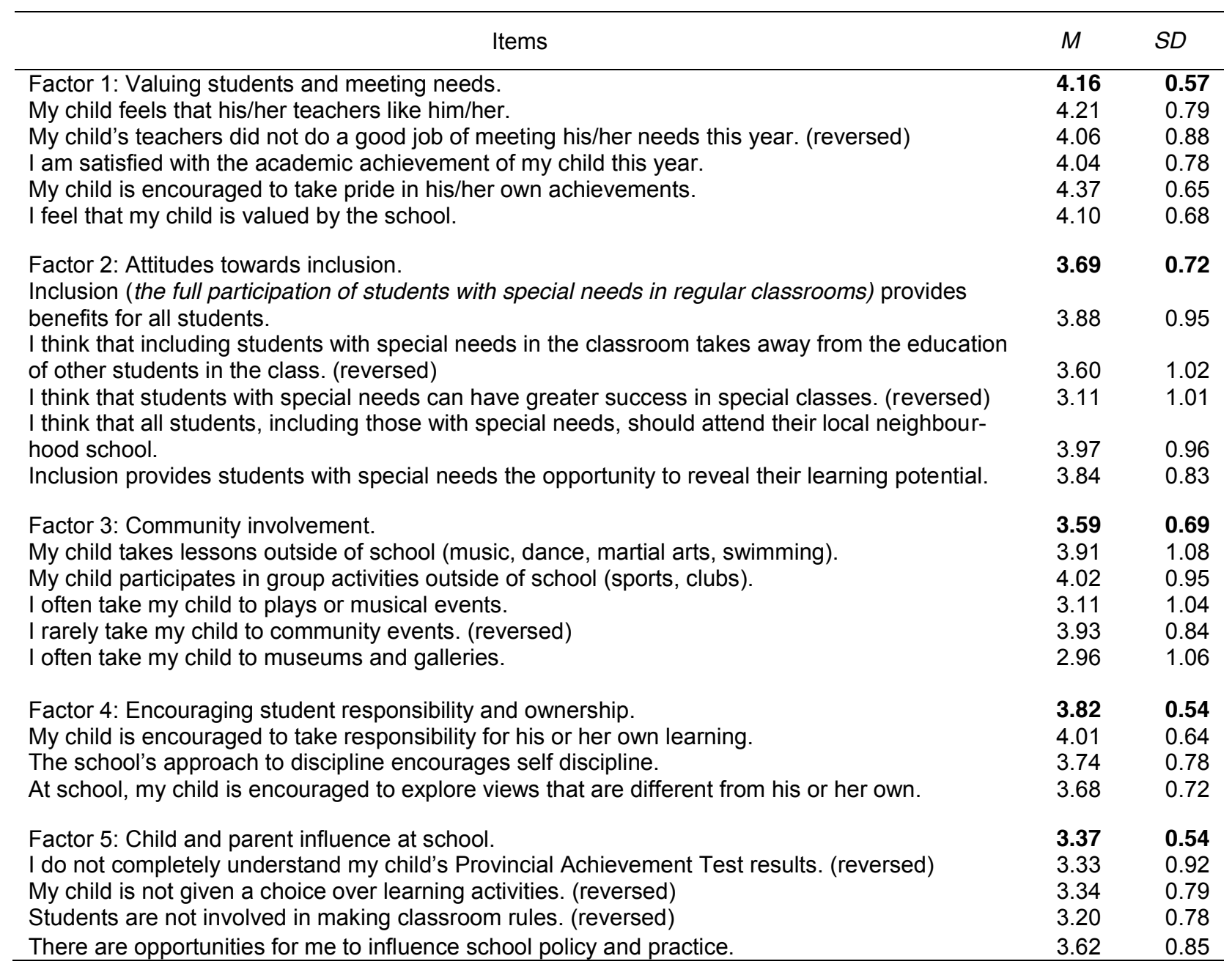

some factors; however, statistical power using eta squared was weak and given the relatively small number of men in the sample $(n=33)$, it was decided that this line of analysis could not be adequately substantiated.

Due to the small numbers of children included in some of the Alberta special education categories, the use of multivariate procedures to discover differences in responses between these categories was not appropriate. As an alternative, in order to see if parents of children who were identified as having an exceptionality differed in their responses from parents of children who were not, an independent-samples $t$ test was conducted for the entire scale and each of the factors. On Factor Three (community involvement), there was a significant difference in scores, $t(419)=2.585, p=.011$, for parents of children who were identified with an exceptionality $(M=$ $3.37, S D=0.872)$ and parents of children who were not $(M=3.64, S D=0.641)$. The magnitude of the differences in the means (mean difference $=.275,95 \%$ CI: .064 to .487 ) was small (eta squared $=.02$ ). Parents of children with exceptionalities report less family involvement in their local communities than their counterparts with children who do not have an exceptionality. 


\section{Discussion}

Parents are overall positive in their responses to the survey with a mean score on the scale of $3.74(S D=0.375)$. While in an overall sense parents are positive on each of the subscales, the elevated standard deviations on Factor Two (attitudes towards inclusion) and Factor Three (community involvement) are worthy of comment. These standard deviations suggest that some parents in the division still hold views which are not aligned with support for inclusion, such as the view that having students with exceptionalities in the classroom takes away from the education of other students in the class, and also that students with exceptionalities can have greater success in special classes. Such ideas have been found to be prominent in the literature, with parents supporting inclusion as long as it does not have a negative impact on the class (Hanson et al., 2001; Kniveton, 2004). Further, levels of involvement in the local community seem to vary considerably from parent to parent, especially with respect to extra-curricular events and cultural opportunities such as museums and galleries.

Parents are most positive in their responses on the theme of valuing students and meeting needs $(M=4.16, S D=0.573)$. Parents feel that the teachers in PHRD like their children, and that the children's academic needs are being met in schools that value them and encourage them to take pride in their achievements. Further, the absence of significant differences on any of the demographic variables with respect to this theme shows that parents are positive about this aspect of schooling regardless of the gender of their child, grade level, or presence of exceptionality.

At the other end of the continuum of parent responses in this study was the theme of child and parent influence at school. The response on this theme is still positive $(M=3.37, S D=$ 0.537), however, it was more moderate than the responses on the other subscales. Once again, demographic variables with respect to this theme show that parents respond similarly to this theme regardless of the gender of their child, age, or presence of exceptionality. A further connection of schools to the community, possibly with the parent and student community in the first instance, might improve the school-community connection and responses on this subscale. Indeed, several studies suggest that not only is the parent-school relationship a crucial part of a successful inclusion model, but that it also contributes to the academic achievement of a wide spectrum of students with exceptionalities (Jenson, Sheridan, Olympia, \& Andrews, 1994; Levy, Kim, \& Olive, 2006; Patton, 1994).

Overall, parents do not report low levels of community involvement $(M=3.59, S D=$ 0.69); however, this result is complicated by an important demographic variable. Parents of typically achieving students are not reporting substantially low levels of community involvement with their families $(M=3.64, S D=0.641)$, but parents of children with exceptionalities rated their community participation as significantly lower $(M=3.37, S D=0.872)$ when compared with these parents. There may be several reasons for parents of children with exceptionalities to report a decreased level of community involvement. One is that parents may want their children to develop social and academic skills rather than community skills (Westling, 1997). Skills involving transitioning to the community, such as learning how to find a job or using the transportation system, may simply have a lower priority compared to academic and social involvement. Another reason may be linked to parental self-perception. There is substantial literature to suggest that most parents of children with exceptionalities, specifically those with disabilities, experience difficulties coming to terms with their child's abilities (Oelfusen \& Richardson, 2006; Smith, Oliver, \& Innocenti, 2001; Trute et al., 2007). Having a child with an exceptionality may impact parents' feelings of confidence in managing and comprehending, as 
well as finding meaning in their lives. Such parents may not want to become involved in school or community activities because they have lost confidence in their ability to manage their own lives, let alone become meaningfully engaged as part of a group (Oelfusen \& Richardson, 2006). A third possibility for decreased community involvement may be that parents do not want to expose their children to negative attitudes in the community (Oelfusen \& Richardson, 2006). They may fear that their children may be ostracized and seek to protect them from negative experiences. In support of this latter hypothesis, research shows that when families of students with exceptionalities do report community involvement, they define community as a group of other people with exceptionalities and not the general community at large (Stainton \& Besser, 1998). Finally, it is often reported that most parents of students with exceptionalities would like to become more involved in community activities, but feel they have limited time or resources to do so (Westling, 1997). This is a pragmatic limiting factor, but an important one. Studies suggest that parents of students with disabilities face increased financial expenses due to their child's disability that my limit their involvement in extra activities (Beckman et al., 1998; Seligman, 1993). In addition, Beckman et al. (1998) found that family schedules and transportation to and from community events were deemed to be limiting factors in the community participation of families of children with disabilities. This may be the case in the PHRD as parents of children with exceptionalities need to spend more time with their children and may have reduced economic and social support resources for participation in events (e.g., paying for child care for other children).

The subscales of attitudes towards inclusion and encouraging student responsibility and ownership rated close to the middle when compared to the means of the other subscales. It is noteworthy that neither of these subscales was impacted by demographic variables. What can be said is that parents of children with exceptionalities and those without who responded to this survey hold similar attitudes towards inclusion and also with respect to how their children's schools encourage student responsibility and ownership. In both cases, parents are positive. The importance of parental attitude in the success of inclusion cannot be overstated, although often parents themselves do not realize the importance of their involvement. Gettinger and Guetschow (1998) administered a questionnaire to elementary school parents and teachers about opportunities for parental involvement and effectiveness of parental input in educational decisions. Perhaps surprisingly, teachers rated parents as more effective with children than parents did themselves. Eccles and Harold (1993) similarly noted that parental involvement in school is critical to the healthy development of adolescents. Regardless of developmental stage, it is clear that parental attitude towards education and inclusion is important to not only its success, but is also a key aspect of the health of children as they progress through their education. Yet we know from studies discussed above that even though parental involvement is encouraged from a philosophical and policy-framework point of view, there are significant barriers to shaping a home-school relationship that would support a successful inclusive model in schools (Cole, 2007; Norwich et al., 2005; O'Connor, 2008). Thus, while parents of children both with and without exceptionalities have a relatively positive attitude towards inclusion in this district, whether or not those attitudes have a chance to make a difference in the functioning of the school is yet to be determined.

Finally, parents reported seeing students develop a sense of responsibility and ownership in their own education as important. There is evidence in the literature to suggest that encouraging students to take responsibility for their own learning and actions improves the academic and social behaviours of a wide range of students with exceptionalities (Morocco, Clay, Parker, \& Zigmond, 2006; Rogers, 1994; Ruth, 1994) and may be the reason for parents indicating that this 
is an important characteristic of successful inclusion. By engaging students in their own learning, parents may see students feel more in control of their own behaviours (Ruth, 1994). In addition to the literature above that suggests that students with disabilities who graduate from inclusive schools are better equipped to transition into adult life than those from segregated settings (e.g., Alper \& Ryndak, 1992), the current results suggest that PHRD parents of children with and without exceptionalities view this as a significant result of inclusive education.

\section{Limitations and Future Directions}

As was stated earlier, the low percentage of respondents to the survey (18\% of parents), while adequate for the purposes of statistical analysis, are likely but not necessarily representative of the wider views of parents in the district. Future studies should attempt to elicit higher response rates, which might be achieved through strategies such as more effective advance notice, follow-up reminders, monetary incentives, and an increased sense of issue salience (Roth \& BeVlier, 1998). Another limitation relates to the request that parents focus on experiences with their youngest child when responding to the survey. This was done in order to ensure some consistency in the responses by focusing parents on a single child; however, it had the effect of skewing responses in the direction of younger grades. This might have produced more positive results than if the survey was administered to parents considering a more equal distribution of age ranges, as parents of younger children can have a tendency to be more positive about inclusive education (Kasari et al., 1999; Leyser \& Kirk, 2004).

Future quantitative studies might wish to elicit a wider array of demographic information from parents, including such factors as salaries and cultural background. This continuation of this research, however, is probably best informed through the conduct of qualitative case studies investigating the themes raised in this study. This will provide for a deeper investigation of the issues at hand. Indeed, this is the direction this project plans to take in the years to follow and which is already underway.

\section{Conclusion}

This study found a generally positive parental view of the work being done in PHRD with respect to important aspects of inclusive education on five subscales important to the success of inclusive education, namely parental perceptions of how their child is valued, and how their needs are met, at school; parental attitudes towards inclusion; levels of family community involvement; parent ideas about the encouragement of a sense of personal responsibility in students; and parental and child influence over activities in the school, and levels of input into decisions. Parents of children with identified exceptionalities report lower levels of community involvement when compared with parents of children who do not have identified exceptionalities, possibly as the result of fear of community attitudes, and financial and logistical reasons. This finding supports other research findings relating to levels of community involvement of families who have children with exceptionalities.

Any number of studies suggest that parental support is essential to the success of inclusion (Leyser \& Kirk, 2004; Swick \& Hooks, 2005), and while this study demonstrates that the work being done by a school district that follows a philosophy of full inclusion can be viewed positively by the parent community, it also points to some areas of tension which might warrant 
further examination both at the level of PHRD and in the wider research community. For example, what might be done to allow families with children with exceptionalities to enjoy more community involvement? Further, as has been discussed, while on the whole positive, parents were by no means unanimous in their level of comfort with inclusive education. What might be done to promote more positive views amongst those parents who dissented from the more common positive views about inclusion? These questions are yet to be adequately addressed in research and deserve some attention if understanding about and acceptance of inclusive education is to become more widespread.

\section{References}

Alper, S., \& Ryndak, D. L. (1992). Educating students with severe handicaps in regular classes Elementary School Journal, 92(3), 373-387.

Andrews, J., \& Lupart, J. L. (2000). The inclusive classroom: Educating exceptional children (2nd ed.). Scarborough, ON: Nelson Canada.

Bartlett, M. S. (1954). A note on the multiplying factors for various chi square approximations. Journal of the Royal Statistical Society, 16(Series B), 296-298.

Beckman, P. J., Barnwell, D., Horn, E., Hanson, M. J., Gutierrez, Su., \& Lieber, J. (1998). Communities, families, and inclusion. Early Childhood Research Quarterly, 13, 125-150.

Bennett, D. B., Deluca, D., \& Bruns, D. (1997). Putting inclusion into practice: Perspectives of teachers and parents. Exceptional Children, 64(1), 115-132.

Brodin, J., \& Lindstrand, P. (2007). Perspectives of a school for all. International Journal of Inclusive Education, 11(2), 133-145. doi:10.1080/13603110500375549.

Bush, C. (2005). Inclusion services for disabled children. Practice, 17(2), 127-130.

Catell, R. B. (1966). The scree test for number of factors. Multivariate Behavioural Research, 1, 245276.

Cole, B. (2007). Mothers, gender, and inclusion in the context of home-school relations. Support for Learning, 22(4), 165-173.

Costello, A. B., \& Osborne, J. W. (2005). Best practices in exploratory factor analysis: Four recommendations for getting the most from your analysis. Practical Research, Assessment, and Evaluation, 10(7), 1-9.

Davern, L., \& Schnorr, R. (1991). Public schools welcome students with disabilities as full members. Children Today, 20(2), 21-25.

Dey, E. L. (1997). Working with low survey response rates: The efficacy of weighting adjustments. Research in Higher Education, 38(2), 215-227.

Duhaney, L. M. G., \& Salend, S. J. (2000). Parental perceptions of inclusive educational placements. Remedial and Special Education, 21(2), 121-128.

Eccles, J. S, \& Harold, R. D. (1993). Parent-school involvement during the early adolescent years. Teachers College Record, 94(3), 568-587.

Gettinger, M., \& Guetschow, K. W. (1998). Parental involvement in schools: Parent and teacher perceptions of roles, efficacy, and opportunities. Journal of Research \& Development in Education, $32(1), 38-52$.

Hadadian, A., \& Merbler, J. (1995). Fathers of young children with disabilities: How do they want to be involved? Child \& Youth Care Forum, 24(5), 327-338.

Hanson, M., Horn, E., Sandall, S., Beckman, P., Morgan, M., Marquart, J., et al. (2001). After preschool inclusion: Children's educational pathways over the early school years. Exceptional Children, 68(1), 65-83. 
Hunt, P., Farron-Davis, F., Beckstead, S., Curtis, D., \& Goetz, L. (1994). Evaluating the effects of placement of students with severe disabilities in general education versus special classes. Journal of the Association for Persons with Severe Handicaps, 19, 200-214.

Jenkinson, J. C. (1998). Parent choice in the education of students with disabilities. International Journal of Disability, Development and Education, 45(2), 189-202.

Jenson, W. R., Sheridan, S. M., Olympia, D., \& Andrews, D. (1994). Homework and students with learning disabilities and behavior disorders: A practical, parent-based approach. Journal of Learning Disabilities, 27(9), 538-548.

Kaiser, H. (1970). A second generation Little Jiffy. Psychometrika, 35, 401-415.

Kaiser, H. (1974). An index of factorial simplicity. Psychometrika, 39, 31-36.

Kalyva, E., Georgiadi, M., \& Tsakiris, V. (2007). Attitudes of Greek parents of primary school children without special educational needs to inclusion. European Journal of Special Needs Education, 22(3), 295-305.

Kasari, C., Freeman, S., Bauminger, N., \& Alkin, M. (1999). Parental perspective on inclusion: Effects of autism and Down syndrome. Journal of Autism and Developmental Disorders, 29(4), 297-306.

Kennedy, C. H., \& Shukla, S. (1997). Comparing the effects of educational placement on the social relationships of intermediate school students with severe disabilities. Exceptional Children, 64(1), $31-48$.

Kishi, G. S., \& Meyer, L. H. (1994). What children report and remember: A six-year follow-up of the effects of social contact between peers with and without severe disabilities. Journal of the Association for Persons with Severe Handicaps, 19(2), 277-289.

Kniveton, B. H. (2004). A study of perceptions that significant others hold of the inclusion of children with difficulties in mainstream classes. Educational Studies, 30(3), 331-343.

Levy, S., Kim, A-H., \& Olive, M. L. (2006). Interventions for young children with autism: A synthesis of the literature. Focus on Autism and Other Developmental Disabilities, 21(1), 55-62.

Leyser, Y., \& Kirk, R. (2004). Evaluating inclusion: An examination of parent views and factors influencing their perspectives. International Journal of Disability, Development, and Education, 52(3), $271-285$.

Loreman, T. (1999). Integration: Coming from the outside. Interaction, 13(1), 21-23.

Loreman, T., Lupart, J. L., McGhie-Richmond, D., \& Barber, J. (2008). The development of a Canadian instrument for measuring student views of their inclusive school environment in a rural context: The Student Perceptions of Inclusion in Rural Canada (SPIRC) scale. International Journal of Special Education, 23(3), 78-89.

Loreman, T., McGhie-Richmond, D., Barber, J., \& Lupart, J. L. (2008). Student perspectives on inclusive education: A survey of grade 3-6 children in rural Alberta, Canada. International Journal of Whole Schooling, 5(1), 1-15.

Lupart, J. L., Whitley, J., Odishaw, J., \& McDonald, L. (2006). Whole school evaluation and inclusion: How elementary school participants perceive their learning community. In C. Dionne \& N. Rousseau (Eds.), Transformation of educational practices: Research on inclusive education (pp. 113143). Quebec: Presses de l'Universite du Quebec.

McDonnell, J., Hardman, M., Hightower, J., \& Kiefer-O'Donnell, R. (1991). Variables associated with in-school and after-school integration of secondary students with severe disabilities. Education \& Training in Mental Retardation, 26(3), 243-252.

McGhie-Richmond, D., Barber, J., Lupart, J., \& Loreman, T. (2009a). The development of a Canadian instrument for measuring teacher views of their inclusive school environment in a rural context: The Teacher Perceptions of Inclusion in Rural Canada (TPIRC) scale. Manuscript submitted for publication.

McGhie-Richmond, D., Barber, J., Lupart, J., \& Loreman, T. (2009b). Teacher perspectives on inclusive education in rural Alberta, Canada. Manuscript submitted for publication.

Morocco, C., Clay, K., Parker, C. E., \& Zigmond, N. (2006). Walter Cronkite High School: A culture of freedom and responsibility. Learning Disabilities Research \& Practice, 21(3), 146-158. 
Muhlenhaupt, M. (2002). Family and school partnerships for IEP development. Journal of Visual Impairment \& Blindness, 96(3), 175-198.

National Educational Association of Disabled Students (NEADS). (2008). Jobpostings. Winter edition.

Norwich, B., Griffiths, C., \& Burden, B. (2005). Dyslexia-friendly schools and parent partnerships: Inclusion and home-school relationships. European Journal of Specials Needs Education, 20(2), 147165.

O'Connor, U. (2008). Meeting in the middle? A study of parent-professional relationships. European Journal of Special Needs Education, 23(3), 253-268.

Oelfusen, N., \& Richardson, P. (2006). Sense of coherence and parenting stress in mothers and fathers of preschool children with developmental disability. Journal of Intellectual \& Developmental Disability, 31(1), 1-12.

Osler, A., \& Osler, C. (2002). Inclusion, exclusion and children's rights: A case study of a student with Asperger syndrome. Emotional and Behavioral Difficulties, 7(1), 35-54.

Patton, J. R. (1994). Practical recommendations for using homework with students with learning disabilities. Journal of Learning Disabilities, 27(9), 570-578.

Prezant, F., \& Marshak, L. (2006). Helpful actions seen through the eyes of parents of children with disabilities. Disability \& Society, 21(1), 31-45. doi:10.1080/09687590500373767.

Rogers, F. (1994). That which is essential is invisible to the eye. Young Children, 49(5), 33.

Roth, P. L., \& BeVlier, C. A. (1998). Response rates in HRM/OB survey research: Norms and correlates, 1990-1994. Journal of Management, 24(1), 97-117.

Ruth, W. J. (1994). Goal setting, responsibility training, and fixed ratio reinforcement: Ten-month application to students with emotional disturbance in a public school setting. Psychology in the Schools, 31(2), 146-155.

Saloviita, T., Italinna, M., \& Leinonen, E. (2003). Explaining the parental stress of fathers and mothers caring for a child with an intellectual disability: A double ABCX model. Journal of Intellectual Disability Research, 47(4/5), 300-312.

Seligman, M. (1993). Group work with parents of children with disabilities. Journal for Specialists in Group Work, 18(3), 115-126.

Smith, T. B., Oliver, M. N., \& Innocenti, M. S. (2001). Parenting stress in families of children with disabilities. American Journal of Orthopsychiatry, 71(2), 257-261.

Stainton, T., \& Besser, H. (1998). The positive impact of children with an intellectual disability on the family. Journal of Intellectual and Developmental Disability, 23(1), 57-70.

Statistics Canada. (2008). Participation and Activity Limitation Survey: Employment. Retrieved March 24, 2009, from http://www.statcan.gc.ca/daily-quotidien/080724/dq080724a-eng.htm

Staub, D., Spaulding, M., Peck, C. A., Gallucci, C., \& Schwartz, I. S. (1996). Using nondisabled peers to support the inclusion of students with disabilities at the junior high school level. Journal of the Association for Persons with Severe Handicaps, 21(4), 194-205.

Swick, K., \& Hooks, L. (2005). Parental experiences and beliefs regarding inclusive placements of their special needs children. Early Childhood Education Journal, 32(6), 397-402.

Thurstone, L. L. (1947). Multiple factor analysis. Chicago: University of Chicago Press.

Trute, B., Hiebert-Murphy, D., \& Levine, K. (2007). Parental appraisal of the family impact of childhood developmental disability: Times of sadness and times of joy. Journal of Intellectual \& Developmental Disability, 32(1), 1-9.

Westling, D. (1997). What parents of young children with mental disabilities want: The views of one community. Focus on Autism and Other Developmental Disabilities, 12, 67-78.

\section{Authors' Note}

Correspondence concerning this article should be addressed to Tim Loreman, Faculty of Education,

Concordia University College of Alberta, Edmonton, AB, T5B 4E4. Email: tim.loreman@concordia.ab.ca 